\title{
HIGHLIGHTS
}

IBD

\section{PPAR $\gamma$ is a key component of the colonic antimicrobial immune system}

Peroxisome proliferator-activated receptor $\gamma(\operatorname{PPAR} \gamma)$ has been identified as a key component of the antimicrobial immune system in the colon, according to the results of a new study.

The gut microbiota is disturbed in patients with Crohn's disease. 'Patients' mucosa is characterized by defective expression of antimicrobial host peptides, including defensins," explain Mathias Chamaillard and Jan Wehkamp, two of the authors of the study. "We believe that failure to prevent the microbial burden of certain pathogens may lead to exaggerated immunological responses."

PPAR $\gamma$ is known to be important in intestinal homeostasis but its role in host defense is less well defined. The authors therefore decided to investigate the role of PPAR $\gamma$ in regulating antimicrobial peptides (particularly $\beta$-defensin) in the intestinal mucosa of patients with Crohn's disease.
The authors searched the regulatory region of $\beta$-defensin for potential binding sites for PPAR $\gamma$, and used data from mouse models of PPAR $\gamma$ deficiency and from patients with Crohn's disease.

"Deficiency of PPAR $\gamma$ was linked to impaired expression of a subset of $\beta$-defensins and to defective killing activity against major groups of commensal microorganisms," report Chamaillard and Wehkamp. The authors suggest that PPAR $\gamma$ has a key role as an antimicrobial factor by maintaining expression of $\beta$-defensin in the colon.

"The development of mucosal delivery systems of PPAR $\gamma$ agonists is now eagerly awaited," the authors conclude.

Isobel Franks

Original article Peyrin-Biroulet, L. et al. Peroxisome proliferator-activated receptor gamma activation is required for maintenance of innate antimicrobial immunity in the colon. Proc. Natl Acad. Sci. USA 107, 8772-8777 (2010) 